in Asia. The current motivations to reconsider higher education curriculum are related to 2 Ist concerns and the need to respond to the needs of the labor market, but the underlying verities of liberal education remain as valid now as they did in the time of Confucius, the Buddha, and Islamic sages.

\section{Neo-Nationalism: Challenges for International Students}

\section{JENNY J. LEE}

Jenny J. Lee is professor of higher education at the University of Arizona, US. E-mail: Jennylee@arizona.edu.

$\mathrm{T}$ here are more students studying outside their borders than ever before, with numbers doubling over the past decade, and forecasts that these numbers will rise even more rapidly in the years to come. Yet, with the rise of international demand, come added challenges for universities seeking to become more globally adaptive to their internationally diverse students. While some cultural adjustment is to be anticipated, what international students might be less prepared for are difficulties that are attributable less to any shortcomings of the student, but to the shortcomings of the home environment. Despite institutional leaders' best efforts, members of the university and local community might not be prepared or willing to welcome those perceived as outsiders. Resistance against international students has been well documented in various media outlets, in the form of discriminatory acts, from subtle stereotyping to physical attacks.

Although most international students have a very positive experience studying abroad, there are others who suffer silently. Based on some recent survey research of international students across seven universities in South Africa, when asked to whom they would report if they encountered unfair treatment, 32 percent indicated that they would not report to anyone.

\section{Rise in Regional Mobility}

With the rise in global mobility, there has been a rise in regional mobility as well. International study within one's region is occurring most notably within the European Union, but regional study is also taking place in East Asia, Latin America, Southern Africa, and other parts of the world. Due to regional cooperation agreements, improved university quality, and increased cross-border travel, there has been an emergence of regional hubs that are attracting increasing numbers of students seeking an international degree, but desiring to stay closer to home. With this phenomenon, one might suppose there would be fewer discriminatory concerns for those maybe appearing less like "foreigners" abroad. Challenges such as language barriers, homesickness, and cultural adaptation might be assumed to be less troubling for those from neighboring countries than those from more distant regions. However, this is not the case.

\section{Neo-nationalism}

In the United States, international students from non-Western and developing countries tended to report more unfair treatment and hostility than students from Europe, Canada, and Australia, which I describe as forms of neo-racism. Neo-racism is discrimination not solely based on biological differences, but also includes differences in culture in this postcolonial era. Neo-racism would help to explain why students from China, for example, might encounter a very different set of troubles in the United States, in comparison to Chinese American students. Neo-racism, however, would not aptly apply to international students being discriminated against within their region. As such, my latest research has uncovered a new form of discrimination that has less to do with one's race and more to do with one's nationality. Whereas nationalism refers to identification with one's nation, neo-nationalism, like neo-racism, extends this concept to the new global economy. Simply put, neo-nationalism is defined as discrimination based on national identity. With increasing internationalization, national identity is being reintroduced and reconceptualized as forms of global competition. That is, neo-nationalism has the potential to negatively impact an international student's experience, particularly in studying in one's region. Negative treatment might occur even despite sharing the same race as the majority culture, and may even result in worse treatment compared to a student from a different race and geographical region.

\section{Cases of South Korea and South Africa}

South Korea and South Africa are two emerging market countries that have both experienced major increases in immigration, including from international students. These countries play significant roles as regional hubs, providing international higher education to nearby countries. Among both overall migrants and cross-border students, the major source of these populations comes from shared borders. Meanwhile, both South Korea and South Africa, much like the major global destinations of the West, have also been subject to negative reports of hostile treatment targeted against unwanted "foreigners." 
South Korea hosts approximately 86,000 international students and attracts most of this population from China (69\%). In a comparison between students from different regions, East Asian students reported greater difficulties and unfair treatment compared to students from Europe, North America, and even other parts of Asia. Chinese students in particular reported feeling less welcomed compared to those from other countries, including other East Asian countries. A Chinese student explained, "Korean students tend to socialize well with students from Western countries and also not bad with Japanese students. But they don't do so with, particularly, Chinese students." Such ex-

\section{Resistance against international stu- dents has been well documented in various media outlets, in the form of discriminatory acts, from subtle stereo- typing to physical attacks.}

periences were explained as based on negative stereotypes about China, and were manifest in a range of discriminatory acts. Common examples included the following: "I made my best effort to search jobs but I was rejected since I was foreigner. Actually, managers didn't recognize it while we were speaking, but I told them honestly since I thought I should not be embarrassed of being Chinese. Then, soon they rejected me." Another student said, "The dorm mother said she never accepted Chinese to live here, since they were dirty and noisy." Such accounts cannot be explained as discrimination by race, but based on national origins.

Such discrimination based on nationality, despite sharing the same race, is not isolated to East Asia. In the case of South Africa, the majority of its approximately 73,000 international students are from Southern Africa (74\%), with the largest group from its border country, Zimbabwe $(27 \%)$. As in South Korea, international students in South Africa reported mistreatment on the basis of nationality. A student explained, "Zimbabweans are treated badly because of our political and economic challenges." Another African student shared, "People seem to be uncomfortable with my being Nigerian." Accommodation is a common problem for international students; as one Zambian student reported, "We as foreigners are usually treated with contempt by South Africans. When it comes to accommodation, we are treated unfairly. We would be charged twice the amount that South African citizens pay." In comparison to other international students, a student from Malawi explained, "Home students are more welcoming to students outside Africa than to those from within Africa... home students do not associate with African international students. However they are always friendly to those coming from overseas."

\section{Complex Challenges Ahead}

Although the dominant hosts in the West continue to grapple with successfully integrating international with local students, similar challenges exist for regional hosts, despite educating a majority of culturally similar international students. While neo-racism might be observed in major Western destinations, such as the United States, United Kingdom, and Australia, neo-nationalism might also be at play, particularly in emerging economies that serve as educational destinations within the region, such as South Korea and South Africa. As some recent research has revealed, the difficulties that international students encounter are global. Even so, neo-racism and neo-nationalism are two different but powerful challenges in this increasingly complex global society.

\section{Challenges of Student Mobility in Southeast Asia}

\author{
Thu T. Do and Duy N. Pham
}

Thu T. Do is a doctoral student in higher education administration, Saint Louis University. E-mail: tdo1o@slu.edu. Duy N. Pham is a doctoral student in research, educational measurement and psychometrics, University of Massachusetts-Amherst.E-mail: dpham@umass.edu.

Tnfluenced by globalization in the beginning of the 2Ist 1 century, Southeast Asia has experienced a remarkable development of student mobility: The number of Southeast Asian students studying abroad is increasing significantly, and the number of international students in Southeast Asia is gradually increasing. While the benefits of student mobility programs are clear, Southeast Asian countries face several challenges when trying to develop them further.

\section{ReCent DeVelopments}

Southeast Asian countries rank among the top 25 countries of origin for international students studying in the United States, including Vietnam (8), Indonesia (I9), Thailand (20), and Malaysia (24). By 20II, these four countries, plus 